\title{
An Investigation of the Motivational Profile of EAP learners at a Transnational Education English Medium Instruction University
}

\author{
Austin Pack, Xi'an Jiaotong-Liverpool University, University of Liverpool \\ iD https://orcid.org/0000-0002-3861-5620 \\ austincpack@gmail.com
}

\begin{abstract}
The number of transnational education (TNE) higher education institutions (HEI) around the globe is on the rise. This study attempts to examine the motivational profiles of English for Academic Purposes (EAP) learners at a TNE university in Mainland China that uses English as the medium of instruction (EMI). Participants $(N=300)$ were primarily first- and second-year students enrolled in EAP classes. The study relied on an adapted version of a motivational questionnaire (Taguchi et al., 2009) to measure some of the most commonly researched motivation constructs. Findings suggest that these students had relatively strong Ideal L2 Selves, were confident in their linguistic abilities, viewed learning EAP as being beneficial for their lives, and desired to integrate with or become like members of their respective academic or professional communities. No meaningful significant differences were found between the motivational profiles of male and female students. This Work-in-Progress study serves as an initial step towards understanding the motivational profiles of EAP learners within the TNE EMI context.
\end{abstract}

Keywords: motivation, transnational education, English medium instruction, English for academic purposes 


\section{INTRODUCTION}

The past two decades have seen an increase in the number of transnational education (TNE) higher educational institutions (HEI) around the globe. TNE has been defined as "award- or credit-bearing learning undertaken by students who are based in a different country from that of the awarding institution" (O’Mahony, 2014, p. 8). Many TNE HEIs offer English Medium Instruction (EMI) programs. Dearden (2014) defined EMI as "the use of English language to teach academic subjects in countries or jurisdictions where the first language (L1) of the majority of the population is not English" (p.4). The number of students enrolled in TNE EMI institutions is on the rise. In 2016-2017, for example, more students, locations, and universities were involved in UK Higher Education TNE than ever before (Boe, 2018); the number of students enrolled in UK HE TNE programs $(707,915)$ was 1.6 times higher than the number of international students in the UK during the same year, and nearly $85 \%$ of UK HEIs offered TNE degree programs (Boe, 2018).

In the TNE EMI university context students must understand the conventions of academic writing in English (e.g., Hyland, 2009) in order to succeed in their academic endeavors. As such, many TNE EMI programs offer robust English for Academic Purposes (EAP) programs. While there has been a growing interest in understanding students' perceptions of EMI education (see for example, Macaro et al., 2018, for a review of literature on the subject), there is a dearth of research investigating second language (L2) motivation within the TNE EMI context. This paper reports on a work-in-progress study that takes an initial step forward in better understanding L2 motivation in the TNE EMI context by investigating the motivational profile of EAP learners at a Sino-British TNE EMI university in Mainland China.

\section{LITERATURE REVIEW}

Motivation "concerns the direction and magnitude of behavior," including "why people decide to do something, how long they are willing to sustain the activity, and how hard they are going to pursue it" (Dörnyei \& Ushioda, 2011, p. 4). The recognition that motivation plays an important role in successful language learning is reflected in the wide range of studies, models, and theories relating to L2 motivation, including many studies conducted in Mainland China, where the current study took place (e.g., Li, 2014; Taguchi et al., 2009; Xu \& Gao, 2014; You \& Dörnyei, 2016).

However, the English as a Foreign Language (EFL) context of these studies varies greatly in comparison with the current EAP TNE EMI context in question. Whereas students in EFL contexts may study English only in English language classes, students at many TNE EMI universities use English much more broadly as nearly all subject courses are taught in English. At the university where the current study was conducted, for example, English serves as the lingua franca; it is used for academic exchange, lectures, policies, and professional services university-wide. The language learning environment of the TNE EMI student is therefore more expansive and extends further into the students' daily lives than the language learning environment of EFL contexts. Because of the lack of empirical studies on the L2 motivation in the TNE EMI context, a study investigating the motivational profile of EAP learners at a TNE university is worthwhile, as it may provide researchers and educators with insights into what motivates students to study EAP, an essential skill, within this context.

The initial research question that guided the study was:

1. What is the motivational profile of EAP learners at a TNE EMI university?

As previous L2 motivation studies have found that female Chinese students are often more motivated than their male counterparts in the EFL context (e.g., You \& Dörnyei, 2016), an additional research question was adopted to test if there would be any difference between male and female EAP learners in the TNE EMI context:

2. Is there any statistically significant difference between the means of motivation constructs that make up the motivational profile of male and female EAP learners at a TNE EMI university?

\section{Motivation Studies in the TNE and/or EMI Context}

Studies specific to L2 motivation in the TNE EMI context are notably lacking. Macaro et al. (2018) conducted a 
review of 83 studies relating to EMI instruction in higher education throughout the world. They highlighted that positive motivators reported by students to enroll in EMI programs included the perceived instrumental advantages of improving English and gaining access to opportunities to study abroad. Jiang et al. (2019) investigated the implementation of EMI in China, including teachers' practices and perceptions, and ESP medical students' learning motivation and needs. They found that the major motivations for studying ESP were to gain an adequate linguistic ability to read subject literature and find academic information, to be more likely to pass exams, earn credits, and/or get a degree and to improve academic writing skills for the purpose of publishing academic work. The authors argue that student motivation to participate in ESP courses was related to the needs or demands to learn English, as imposed by EMI courses, as well as expectations that would be placed upon students in their future academic or medical careers.

$\mathrm{Du}$ and Jackson (2018) investigated changes in the motivational dynamics of eight Mainland Chinese undergraduate students as they studied at a bilingual university in Hong Kong that used EMI. Participants experienced motivational surges due to specific situational factors such as a study tour abroad or an approaching English proficiency test. The authors argue that long-lasting motivational upward swings were connected to students' perceptions of their ideal L2 selves, other L2 self-concepts, and their context.

Larger scale studies investigating L2 motivation in the TNE EMI context, however, are lacking. Given that TNE EMI programs are relatively new, the field's understanding of L2 motivation within this context has lagged behind its ESL and EFL counterparts. The current study takes an initial step into trying to understand the L2 motivation in the TNE EMI context by generating a motivational profile of EAP learners in a TNE EMI setting.

\section{METHOD}

\section{Participants}

Three hundred students at a Sino-British TNE EMI university located in Mainland China participated in the study. Two students opted out of giving demographic information. Most participants were first $(n=139)$ and second $(n=129)$ year students. A small number of third ( $n$ $=19)$ and fourth $(n=11)$ year students also participated. Ninety-two students identified as male; 206 as female. While the vast majority of students were Chinese nationals $(n=287)$, several international students $(n=11)$ also participated. Students' were majoring in a diverse array of subjects including the sciences, mathematics, international business, design, and the humanities.

\section{Data Elicitation Instrument}

The motivation questionnaire used in the study was adapted from the Taguchi et al. (2009) study (see also Dörnyei \& Ushioda, 2011, pp. 275-283), a questionnaire which was deemed to be a "rounded, robust measure of learners' motivation" (Dörnyei, 2012, as cited in Kikuchi, 2017). Given that the original questionnaire created by Taguchi et al. (2009) was not developed for the EAP or TNE contexts, it was necessary to modify the instrument to make it more suitable for the TNE EMI and EAP context. Some, but not all of the constructs of the original questionnaire were included. These constructs include: Intended Effort, Ideal L2 Self, Instrumentality (promotion), Instrumentality (prevention), Linguistic Self-confidence, Ethnocentrism, Parental Encouragement/Family Influence, Attitudes to Learning English, Attitudes towards L2 Community, Integrativeness, and English Anxiety. The constructs of Cultural Interest, Travel Orientation, Ought-to L2 self, and Fear of Assimilation were not included because they were either (1) deemed irrelevant to the EMI-TNE context, (2) shown in previous studies to not carry as much significance as other constructs in China (see e.g., You \& Dörnyei, 2016; Taguchi et al., 2009), and (3) removed for the sake of reducing the number of items on the motivation questionnaire, as questionnaires that are overly long can be counterproductive (Dörnyei \& Taguchi, 2010).

Furthermore, the motivation constructs of Integrativeness and Attitudes Towards L2 Community were combined into one single concept: Integrativeness. This was done in order to simplify the survey, given that Attitudes Towards L2 Community is arguably a part of Integrativeness (see for example, Gardner's (1985) Integrative Motive, as cited in Dörnyei (1994). The construct Fear of Assimilation was deleted altogether as 
students enrolled in a TNE-EMI university are unlikely to be concerned about losing their Chinese identity, values, or language because of internationalization. In addition, some original items were problematic because the wording related to English courses can be confusing in the EMI-TNE context where all classes are taught in English. The item $I$ have to learn English because I don't want to fail the English course, in the construct of Instrumentality (prevention), for example, is problematic because students could interpret 'English course' in the EMI-TNE context either as students' English for Academic Purposes class, or potentially any of their other classes that are taught in English. To prevent such confusion from occurring, items that might be ambiguous in the TNE-EMI context were modified or separated into two different items to draw a clear distinction between EAP classes and other classes that are taught in English.

Following Dörnyei and Taguchi's (2010) suggestion of conducting an initial piloting of the item pool, the questionnaire was first administered to twenty EAP students who examined the wording in the instructions and items. These students were asked to mark any item whose wording was unclear or confusing in any way. Based on their feedback, minor changes to word choice were made to the instructions and to a few items to enhance clarity. Items were then randomized.

The final questionnaire (see Appendix) included 48 Likert scale items that were divided into two parts. The first part included statement-type items that students answered by using a six-point scale (strongly disagree, disagree, slightly disagree, slightly agree, agree, strongly agree). The second part included question-type items with a six-point response scale (not at all, not so much, so-so, a little, quite a lot, very much). Lastly, the questionnaire included seven items aimed at eliciting demographic information.

\section{Data Collection and Analysis Procedures}

The final questionnaire was administered online via Qualtrics.com. Responses that were incomplete and/or were not given sincerely (answering " 1 " for each Likert scale items) were deleted. This resulted in only a portion $(N=300)$ of the total initial responses $(N=518)$ being used for analysis. Based on the 300 valid responses gathered, the Cronbach Alpha coefficients for multi-scale items were calculated to check for internal consistency of each measured construct. The resulting Cronbach Alpha coefficient for each motivational construct is shown in Table 1. Because all the motivation constructs had a Cronbach Alpha coefficient greater than the suggested lower threshold of .6 (Dörnyei \& Taguchi, 2010, p. 95), and the Cronbach Alpha coefficient for the entire instrument was .86 , the reliability of the instrument was considered acceptable and the data suitable for further data analysis. To answer the first research question, descriptive statistics of each motivation construct were calculated. To answer the second research question, a 2-tailed independent samples $t$ test of the means of each construct for male and female students was computed.

\section{RESULTS}

Descriptive statistics of each motivation construct are given in Table 1. The results of the 2-tailed independent samples $t$-tests of the means of male and female students for each of the motivation constructs are given in Table 2 .

\section{DISCUSSION}

In regard to the first research question, the means of Ideal L2 Self $(M=4.87)$ and Linguistic Self-confidence $(M=4.85)$ constructs suggest that the participants had relatively strong Ideal L2 Selves and were confident in their linguistic abilities. Furthermore, the relatively high means of Instrumentality (Promotion) $(M=4.81)$ and Integrativeness $(M=4.73)$ suggest that these students viewed learning EAP as being beneficial for their lives and that they desired to integrate with or become like members of their respective academic or professional communities. The mean for Instrumentality (Prevention) $(M=4.41)$ was in the lower half of the positive range, suggesting that students were also somewhat motivated to learn English/EAP in order to avoid negative outcomes (e.g., poor marks). Intended Effort ( $M=$ 4.15) was only slightly above the median point of 3.5 , thereby indicating that students felt they only slightly agreed that they were willing to expend energy and time to study EAP. The remaining constructs were all below the median point. These included Attitudes towards Learning English $(M=3.46)$, English Anxiety $(M=3.46)$, Ethnocentrism $(M=2.94)$, and Parental Encouragement / 
Family Influence $(M=2.77)$. These values suggest that students did not hold particularly favorable or unfavorable attitudes towards learning English, were not particularly anxious language learners, that ethnocentrism likely did not negatively affect their motivation, and that influence from parents and other family members did not appear to be a major influence on students' motivation to study English/EAP.

Table 1. Descriptive Statistics for all Motivational Constructs

\begin{tabular}{lccccc}
\hline Motivation Construct & $\begin{array}{c}\alpha \\
\text { coefficient }\end{array}$ & $M$ & $S D$ & Skewness & Kurtosis \\
\hline Ideal L2 Self & .80 & 4.87 & .70 & -.739 & 1.642 \\
Linguistic Self-confidence & .71 & 4.85 & .69 & -.368 & .150 \\
Instrumentality (Promotion) & .72 & 4.81 & .71 & -.769 & .885 \\
Integrativeness & .64 & 4.73 & .70 & -.418 & .118 \\
Instrumentality (Prevention) & .85 & 4.41 & .92 & -.849 & 1.434 \\
Intended Effort & .66 & 4.15 & .72 & -.629 & .734 \\
Attitudes Towards Learning English & .80 & 3.46 & 1.04 & -.434 & -.195 \\
English Anxiety & .83 & 3.46 & 1.05 & -.238 & -.446 \\
Ethnocentrism & .61 & 2.94 & .90 & .066 & -.418 \\
Parental Encouragement / Family Influence & .80 & 2.77 & .96 & .247 & -.462 \\
\hline
\end{tabular}

Note. $N=300$. Skewness $S E=.141$; Kurtosis $S E=.281$.

Table 2. Results of the 2-tailed Independent Samples t-test

\begin{tabular}{lccccccc}
\hline Motivation Construct & $M$ (Male) & $M$ (Female) & $M D$ & $t$ & & & $d$ \\
\hline Ideal L2 Self & & & & & & & \\
Linguistic Self-confidence & 4.89 & 4.86 & .0337 & .380 & .705 & .048 \\
Instrumentality (Promotion) & 4.88 & 4.84 & .033 & .382 & .703 & .048 \\
Integrativeness & 4.72 & 4.85 & -.136 & -1.520 & .130 & .191 & .384 \\
Instrumentality (Prevention) & 4.55 & 4.82 & -.266 & -3.063 & $.002^{*}$ & .057 \\
Intended Effort & 4.37 & 4.42 & -.053 & -.454 & .650 & .057 \\
Attitudes Towards Learning English & 4.05 & 4.19 & -.135 & -1.483 & .139 & .186 \\
English Anxiety & 3.89 & 3.98 & -.090 & -.682 & .496 & .086 \\
Ethnocentrism & 3.33 & 3.52 & -.188 & -1.418 & .157 & .178 \\
Parental Encouragement / Family Influence & 3.13 & 2.85 & .285 & 2.543 & $.012^{*}$ & .319 \\
\hline
\end{tabular}

Note. Male $n=92$, Female $n=206 ; d f$ for all variables $=296$.

$* p=<.05$.

As to the second research question, which asked if there were any statistically significant differences between the motivational constructs that make up the motivation profile of male and female EAP learners at a TNE EMI university, 
the results indicated there were no statistically significant differences between the means of male and female students for the motivation constructs, except for Integrativeness and Ethnocentrism. None of the constructs surpassed the .4 threshold for a 'small' effect size (Plonsky \& Oswald, 2014). These results suggest that there was little difference between the motivational profiles of the male and female EAP learners that participated in the current study.

\section{CONCLUSION}

As the number of TNE HEIs that offer EMI programs is on the rise, there is a growing need to understand the language learners in this context, a context which may be quite different than the ESL and EFL contexts that account for the majority of English language learning in classrooms around the globe. This study has taken an initial step by investigating the motivational profile of students learning EAP at a TNE university that uses EMI in Mainland China. It was found that these students had relatively strong Ideal L2 Selves, were confident in their linguistic abilities, viewed learning EAP as being beneficial for their lives, and desired to integrate with or become like members of their respective academic or professional communities. No meaningful significant differences were found between the motivational profile of male and female students. The study had several limitations: it did not account for the dynamic nature of motivation and the sample size of third- and fourth-year students is too small to ascertain if motivation levels rise or drop across the general student population as students approach the end of their studies. Future avenues of research might include a longitudinal study that explores the dynamics of motivation as students as they progress in their studies at a TNE EMI university.

\section{Ethics Approval \& Consent to Participate}

This study was approved by Xi'an Jiaotong-Liverpool University's Research Ethics Committee. All participants provided written informed consent prior to enrollment and data collection in the study.

\section{Notes on the author}

Austin Pack is a language educator interested in understanding and creating engaging learning experiences. His research interests include the psychology of language learning, complex dynamic systems, network analysis, computer assisted language learning, and virtual reality technologies.

\section{REFERENCES}

Boe, L. (2018). The scale of UK higher education transnational education 2016-17: Trend analysis of HESA data. Retrieved from https://www.universitiesuk.ac.uk/policy-andanalysis/reports/Pages/the-scale-of-UK-highereducation-transnational-education-2015-16.aspx

Dearden, J. (2014). English as a medium of instruction - A growing global phenomenon. British Council. https://www.britishcouncil.org/sites/default/files/e 484 emi - cover_option 3 final_web.pdf

Dörnyei, Z. (1994). Understanding L2 motivation: On with the challenge! The Modern Language Journal, 78(4), 515-523. https://doi.org/10.1111/j.15404781.1994.tb02071.x
Dörnyei, Z., \& Taguchi, T. (2010). Questionnaires in second language research: Construction, administration, and processing (2nd ed.). Routledge.

Dörnyei, Z., \& Ushioda, E. (2011). Teaching and researching motivation (2nd ed.). Pearson.

Du, X., \& Jackson, J. (2018). From EFL to EMI: The evolving English learning motivation of mainland Chinese students in a Hong Kong university. System, 76, 158-169. https://doi.org/10.1015/j.system.2018.05.011

Hyland, K. (2009). Academic discourse. Continuum.

Jiang, L., Zhang, L. J., \& May, S. (2019). Implementing English-medium instruction (EMI) in China: Teachers' practices and perceptions, and students' 
learning motivation and needs. International Journal of Bilingual Education and Bilingualism, 22(2), 107-119.

https://doi.org/10.1080/13670050.2016.1231166

Kikuchi, K. (2017). Reexamining demotivators and motivators: A longitudinal study of Japanese freshmen's dynamic system in an EFL context. Innovation in Language Learning and Teaching, 11(2), 128-145. https://doi.org/10.1080/17501229.2015.1076427

Macaro, E., Curle, S., Pun, J., An, J., \& Dearden, J. (2018). A systematic review of English medium instruction in higher education. Language Teaching, 51(1), 36-76.

Li, Q. (2014). Differences in the motivation of Chinese learners of English in a foreign and second language context. System, 42, 451-461. https://doi.org/10.1016/j.system.2014.01.011

O’Mahony, J. (2014). Enhancing student learning and teacher development in transnational education. The Higher Education Academy. Retrieved from https://www.advance-he.ac.uk/knowledge- hub/enhancing-student-learning-and-teacherdevelopment-transnational-education

Plonsky, L., \& Oswald, F. L. (2014). How big is "big"? Interpreting effect sizes in L2 research. Language Learning, 64, 878-912. https://doi.org/10.1111/lang.12079

Taguchi, T., Magid, M., \& Papi, M. (2009). The L2 Motivational Self System among Japanese, Chinese and Iranian learners of English: A comparative study. In Z. Dörnyei \& E. Ushioda (Eds.), Motivation, language identity and the L2 self (pp. 66-97). Multilingual Matters.

Xu, H., \& Gao, Y. (2014). The development of English learning motivation and learners' identities: A structural equation modeling analysis of longitudinal data from Chinese universities. System, 47, 102-115. https://doi.org/10.1016/j.system.2014.09.020

You, C., \& Dörnyei, Z. (2016). Language learning motivation in China: Results of a large-scale stratified survey. Applied Linguistics, 37(4), 495519. https://doi.org/10.1093/amu046

\section{APPENDIX}

\begin{tabular}{|c|c|c|}
\hline Construct & $\begin{array}{l}\text { Item } \\
\text { Number }\end{array}$ & Item \\
\hline \multirow[t]{5}{*}{ Intended Effort } & A1 & If an EAP course was offered in the future, I would like to take it. \\
\hline & A2 & I am prepared to expend a lot of effort in learning English. \\
\hline & A3 & I think that I am doing my best to learn English. \\
\hline & A4 & I would like to spend lots of time studying English. \\
\hline & A5 & I would like to concentrate on studying English more than any other topic. \\
\hline \multirow[t]{6}{*}{ Ideal L2 Self } & B1 & I can imagine myself living abroad and having a discussion in English. \\
\hline & $\mathrm{B} 2$ & $\begin{array}{l}\text { I can imagine myself working for an international company inside or outside of China where } \\
\text { I use English on a daily basis. }\end{array}$ \\
\hline & B3 & I can imagine myself speaking English with international friends or colleagues. \\
\hline & B4 & $\begin{array}{l}\text { I imagine myself as someone who is able to use English in academic or professional } \\
\text { contexts. }\end{array}$ \\
\hline & B5 & I can imagine myself speaking English fluently in academic or professional contexts. \\
\hline & B6 & $\begin{array}{l}\text { Whenever I think of my future career, I imagine myself using English in academic or } \\
\text { professional contexts. }\end{array}$ \\
\hline \multirow[t]{5}{*}{$\begin{array}{l}\text { Instrumentality } \\
\text { (promotion) }\end{array}$} & C1 & $\begin{array}{l}\text { Studying EAP is important to me because I think it will someday be useful in getting a good } \\
\text { job. }\end{array}$ \\
\hline & $\mathrm{C} 2$ & $\begin{array}{l}\text { Studying EAP is important to me because English proficiency is necessary for getting a } \\
\text { good job. }\end{array}$ \\
\hline & C3 & Studying EAP is important to me because I think I'll need it for further studies. \\
\hline & C4 & Studying EAP is important to me because it offers a new challenge in my life. \\
\hline & C5 & Studying EAP is important to me in order to attain a higher social status. \\
\hline
\end{tabular}




\begin{tabular}{|c|c|c|}
\hline \multirow[t]{6}{*}{$\begin{array}{l}\text { Instrumentality } \\
\text { (prevention) }\end{array}$} & D1 & $\begin{array}{l}\text { I have to learn academic English because I don't want to fail my Language Center EAP } \\
\text { class. }\end{array}$ \\
\hline & D2 & $\begin{array}{l}\text { I have to learn academic English because I don't want to fail non-Language Center classes } \\
\text { that are taught in English. }\end{array}$ \\
\hline & D3 & $\begin{array}{l}\text { I have to study academic English because I don't want to get bad marks in my Language } \\
\text { Center EAP class. }\end{array}$ \\
\hline & D4 & $\begin{array}{l}\text { I have to study academic English because I don't want to get bad marks in non-Language } \\
\text { Center classes that are taught in English. }\end{array}$ \\
\hline & D5 & $\begin{array}{l}\text { Studying EAP is important to me because I would feel ashamed if I got bad grades in my } \\
\text { Language Center EAP class. }\end{array}$ \\
\hline & D6 & $\begin{array}{l}\text { Studying EAP is important to me because I would feel ashamed if I got bad grades in my } \\
\text { non-Language Center classes that are taught in English. }\end{array}$ \\
\hline \multirow{4}{*}{$\begin{array}{l}\text { Linguistic Self- } \\
\text { confidence }\end{array}$} & E1 & If I make more effort, I am sure I will be able to master academic English. \\
\hline & E2 & $\begin{array}{l}\text { I believe that I will be capable of reading and understanding most academic texts in English } \\
\text { if I keep studying EAP. }\end{array}$ \\
\hline & E3 & I am sure I will be able to write academic English without difficulty if I continue to study. \\
\hline & E4 & I am sure I have a good ability to learn academic English. \\
\hline \multirow[t]{4}{*}{ Ethnocentrism } & $\mathrm{F} 1$ & I would be happy if other cultures were more similar to Chinese. \\
\hline & $\mathrm{F} 2$ & It would be a better world if everybody lived like the Chinese. \\
\hline & F3 & Other cultures should learn more from my culture. \\
\hline & F4 & Most other cultures are backward compared to my Chinese culture. \\
\hline Parental & G1 & My family put a lot of pressure on me to study English. \\
\hline Encouragement / & G2 & Studying English is important to me in order to bring honor to my family. \\
\hline \multirow[t]{3}{*}{ Family Influence } & G3 & Being successful in English is important to me so that I can please my parents/relatives. \\
\hline & G4 & I must study English to avoid being punished by my parents/relatives. \\
\hline & G5 & My family put a lot of pressure on me to study abroad. \\
\hline Attitudes & $\mathrm{H} 1$ & Do you find learning academic English really interesting? \\
\hline Towards & $\mathrm{H} 2$ & Do you always look forward to EAP classes? \\
\hline Learning English & $\mathrm{H} 3$ & Do you really enjoy learning academic English? \\
\hline \multirow[t]{5}{*}{ Integrativeness } & $\mathrm{I1}$ & $\begin{array}{l}\text { Do you want to participate in professional or academic events that use English for } \\
\text { communication? }\end{array}$ \\
\hline & 12 & Do you like the people use English fluently within your chosen profession? \\
\hline & 13 & Do you like meeting people from the international community that speak English fluently? \\
\hline & 14 & $\begin{array}{l}\text { Do you think it is important to speak English fluently to be accepted as a member of your } \\
\text { chosen professional community? }\end{array}$ \\
\hline & 15 & $\begin{array}{l}\text { How much would you like to become similar to the people who speak English in your } \\
\text { chosen profession? }\end{array}$ \\
\hline \multirow[t]{5}{*}{ English Anxiety } & $\mathrm{J} 1$ & $\begin{array}{l}\text { How nervous do you get when you are speaking English in your Language Center EAP } \\
\text { class? }\end{array}$ \\
\hline & $\mathrm{J} 2$ & $\begin{array}{l}\text { How nervous do you get when you are speaking English in your non-Language Center, } \\
\text { major specific classes? }\end{array}$ \\
\hline & J3 & $\begin{array}{l}\text { How uneasy would you feel using English to communicate with a professor or expert in your } \\
\text { chosen profession? }\end{array}$ \\
\hline & J4 & How tense would you get if a foreigner asked you for directions on campus in English? \\
\hline & $\mathrm{J} 5$ & How afraid are you of sounding stupid in English because of the mistakes you make? \\
\hline
\end{tabular}

